\title{
Ozone vertical variations during a typhoon derived from the OMI observations and reanalysis data
}

\author{
FU YunFei ${ }^{1,2,3^{*}}$, XIAN Tao $^{1}$, LÜ DaRen ${ }^{3}$, LIU GuoSheng ${ }^{1,4}$, HENG ZhiWei ${ }^{1}$, SUN Liang ${ }^{1}$,

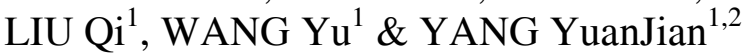 \\ ${ }^{1}$ Laboratory of Atmospheric Observation and Climatological Environment, School of Earth and Space Sciences, University of Science and \\ Technology of China, Hefei 230026, China; \\ ${ }^{2}$ Key Laboratory of Atmospheric Composition and Optical Radiation, Anhui Institute of Optics and Fine Mechanics, Chinese Academy of Sciences, \\ Hefei 230031, China; \\ ${ }^{3}$ LAGEO, Institute of Atmospheric Physics, Chinese Academy of Sciences, Beijing 100029, China; \\ ${ }^{4}$ Department of Meteorology, Florida State University, Tallahassee, FL 32306-4520, USA
}

Received March 21, 2013; accepted July 3, 2013; published online August 7, 2013

\begin{abstract}
Typhoon is considered to play a key role in the dynamical exchange processes taking place between the troposphere and stratosphere. In this paper, the impact of typhoon on the ozone distribution in the upper troposphere and middle stratosphere is investigated using ozone profiles measured by Aura's Ozone Monitoring Instrument and meteorological fields from reanalysis data. During the passage of Typhoon Hai-Tang in 2005 over the western North Pacific, low values of ozone column above $200 \mathrm{hPa}$ and ozone mixing ratio between the upper troposphere and the middle stratosphere (from 200 to $50 \mathrm{hPa}$ ) are observed right above the typhoon's track, a result due to the strong upward propagation of air associated with overshooting convection in typhoon. A comparative analysis of different stages of Hai-Tang suggests that in the region where typhoon has higher intensity the troposphere-to-stratosphere transport is enhanced. These results indicated that the typhoon has a significant impact on the ozone variation in the upper troposphere and the middle stratosphere.
\end{abstract}

typhoon, overshooting convection, Ozone Monitoring Instrument, ozone vertical profiles, ozone distribution

Citation: Fu Y F, Xian T, Lü D R, et al. Ozone vertical variations during a typhoon derived from the OMI observations and reanalysis data. Chin Sci Bull, 2013, 58: 3890-3894, doi: 10.1007/s11434-013-6024-7

Deep convection in typhoons (or tropical cyclones) provides a preferred condition for stratosphere-troposphere exchange $[1,2]$ that causes the variability of ozone in the upper troposphere and lower stratosphere. The injection of tropospheric ozone-poor air into the lower stratosphere near the typhoon's eye has been observed based on the aircraft measurements [3-7] and satellite data [8-11]. Moreover, stratospheric ozone-rich air intrusion into the troposphere due to the subsidence in the eye of typhoons has been reported $[3,5,12,13]$. These typhoon-related ozone episodes are generally believed to be the results of tropospheric air upwelled by deep convection and ozone-rich stratospheric air down-

*Corresponding author (email: fyf@ustc.edu.cn) welled by intrusion $[6,8,10,13]$. Although there are discrepancies between the total column ozone derived from satellites and aircraft observations in typhoons' eyes [7,12], the regions of high column ozone inside the eye regions are observed during intense stages of typhoons [6]. Additionally, typhoon not only influences the local ozone budget, but also has an impact on the ozone meridional transport [14]. Based on backward trajectory analysis, ozone transported between midlatitude and tropics was influenced by the large-scale circulation coupled with a typhoon $[7,14,15]$.

However, the variability of ozone vertical structure during the typhoon processes has not been well investigated. Fortunately, the Ozone Monitoring Instrument (OMI) launched on the National Aeronautics and Space Administration 
(NASA) Aura platform in July 2004 [16] provides a unique opportunity to investigate ozone vertical distribution extending from troposphere to stratosphere. In this study, Typhoon Hai-Tang in July 2005 is captured by OMI over the western North Pacific. A comparative analysis of different stages of Hai-Tang, category 1 on 13 July and category 4 on 17 July, was conducted to examine the different contributions of weak and intense typhoons to the exchange between troposphere and stratosphere. Two square regions, S1 and S2, which are occupied by the centers of Hai-Tang at 0600 UTC on 13 July and at 0600 UTC on 17 July, are selected. Ozone statuses within the selected regions during the typhoon's passage (hereafter called TC), before the typhoon (hereafter called pre-TC) on 11 July, and after the typhoon (hereafter called post-TC) on 15 July for S1 and 17 July for $\mathrm{S} 2$ are calculated for comparison.

Two remote sensing data sets, i.e. the average rain rate between 2 and $4 \mathrm{~km}$ from the Tropical Rainfall Measuring Mission (TRMM) precipitation radar (PR) 2A25 data and ozone profiles from the version 3 OMO3PR products of
OMI are used in this work. The rain rate data with a horizontal resolution of $4.5 \mathrm{~km}$ is available at the Tropical Cyclone Database (http://www.eorc.jaxa.jp/TRMM/typhoon) maintained by the Japan Aerospace Exploration Agency (JAXA)/Earth Observation Research and application Center (EORC). The ozone profiles are provided by the NASA Goddard Earth Sciences (GES) Data and Information Services Center (DISC) (http://disc.sci.gsfc.nasa.gov/Aura/dataholdings/OMI). The ozone profiles are given in terms of the layer-columns of ozone in Dobson Unit (DU) for an 18layer atmosphere, with the layers nominally bounding by the pressure levels (surface pressure, 700, 500, 300, 200, $150,100,70,50,30,20,10,7,5,3,2,1,0.5,0.3 \mathrm{hPa})$. The data have a horizontal resolution of $65 \mathrm{~km} \times 48 \mathrm{~km}$. The comparison of ozone profiles from OMI and Microwave Limb Sounder (MLS) [17] shows that OMI ozone profiles in the northern sub-tropics $\left(15^{\circ}-30^{\circ} \mathrm{N}\right)$ show a bias of $-15 \%-10 \%$ and the standard deviations of the differences are $2 \%-7 \%$ above $50 \mathrm{hPa}$ and within $12 \%$ between $50-215$ $\mathrm{hPa}$. Moreover, ozone column above $200 \mathrm{hPa}$ (OC200) was
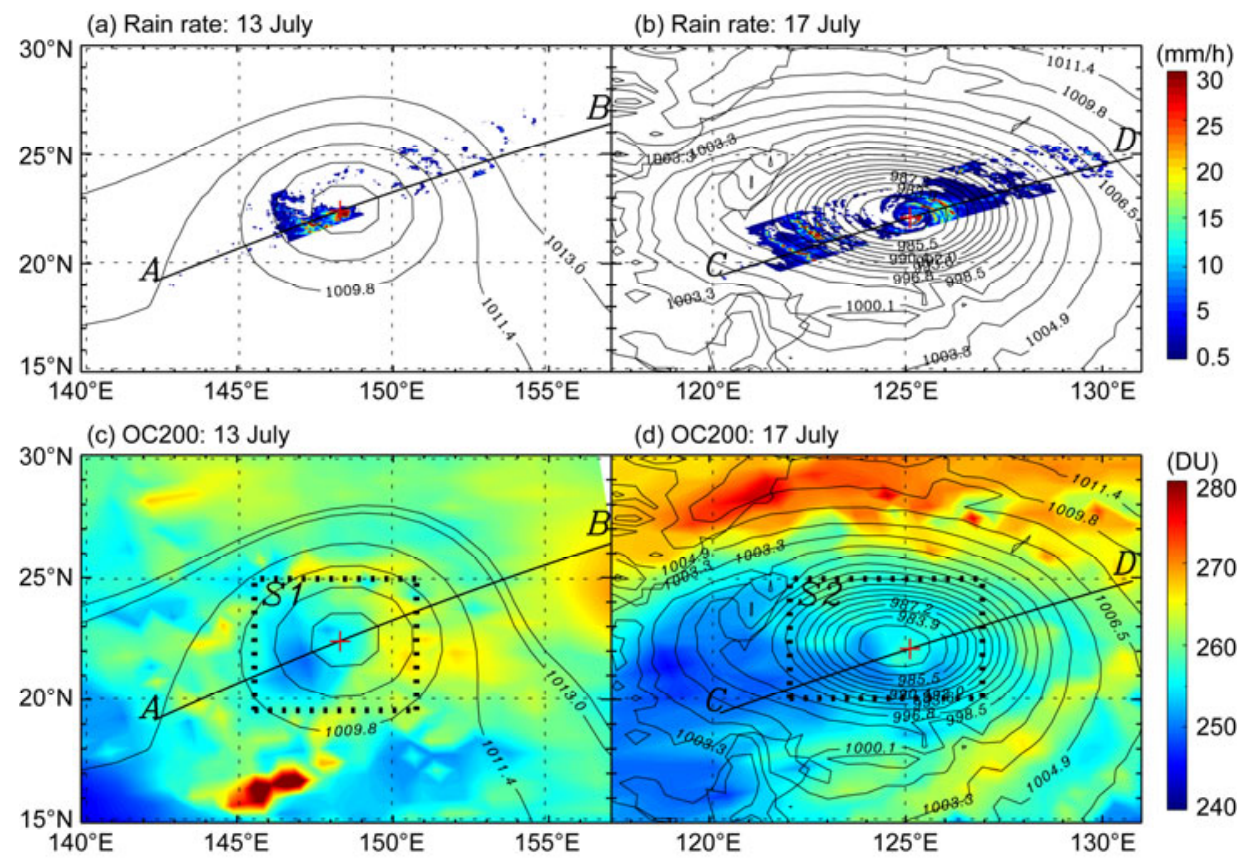

(d) OC200: 17 July
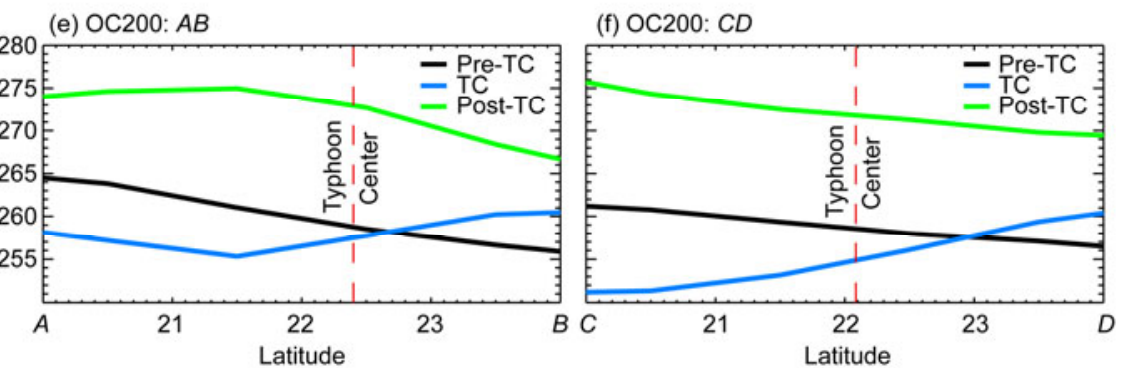

Figure 1 (a) and (b) Rainfall rate (shaded: $\mathrm{mm} \mathrm{h}^{-1}$ ) and sea level pressure (contour: hPa), and (c) and (d) OC200 (shaded: DU) with sea level pressure (contour) at 0600 UTC 13 July and 0600 UTC 17 July, respectively. The southwest-northeast cross sections of ozone were shown by the black lines $A B$ and $C D$; the eyes of typhoon were indicated by red crosses; the research areas for mean ozone profiles were shown by dotted squares S1 and S2. (e) and (f) OC200 (unit: DU) along lines $A B$ and $C D$ before (pre-TC), during (TC) and after (post-TC) Hai-Tang, respectively. The red dotted lines indicated the locations of typhoon eye. 
employed. Liu et al. [18] in 2010 demonstrated that OMI retrieval errors in stratospheric ozone columns down to 215 $\mathrm{hPa}$ are 1.6-4 DU. Additionally, the effect of cloud in the troposphere can be negeleted in this ozone column product.

In addition, the sea level pressure (SLP) and vertical velocities at $500 \mathrm{hPa}\left(\omega_{500}\right)$ on $1^{\circ} \times 1^{\circ}$ grid at every six hours (0000, 0600, 1200, and 1800 UTC) based on National Centers for Environmental Prediction (NCEP) Climate Forecast System Reanalysis data (http://cfs.ncep.noaa.gov/cfsr/) are used to quantify the typhoon's strength. The potential vorticity (PV) obtained from European Centre for MediumRange Weather Forecasting (ECMWF) reanalysis project (ERA-Interim) was used as a dynamical tracer for the exchange process between troposphere and stratosphere. The $\mathrm{PV}$ data are available four times daily on a $0.75^{\circ} \times 0.75^{\circ}$ grid with 37 pressure levels from 1000 to $1 \mathrm{hPa}$.
Typhoon Hai-Tang formed on 11 July 2005 in the western subtropical Pacific. As it moved westward, it continued to gain strength and reached category 5 on 16 July. HaiTang landed on eastern coast of Taiwan as a category-3 typhoon on 18 July. OMI provides relatively complete measurements on 13 and 17 July, 2005, when Hai-Tang was located at $22.4^{\circ} \mathrm{N}, 148.3^{\circ} \mathrm{E}$ and at $22.1^{\circ} \mathrm{N}, 125.1^{\circ} \mathrm{E}$ reaching category 1 and 4, respectively. As depicted in Figure 1(a), asymmetric precipitation of Hai-Tang was evident on 13 July. Similar asymmetric typhoon rainfall with a larger rainfall area was observed on 17 July in Figure 1(b). Figure 1(c) displays that a relatively lower OC200 (250 DU) coincided with larger rain rates $\left(>5 \mathrm{~mm} \mathrm{~h}^{-1}\right)$ occurred in the southwest quadrant of Hai-Tang, while higher OC200 (>260 DU) was accompanied with lower rain rates $\left(<0.5 \mathrm{~mm} \mathrm{~h}^{-1}\right)$. OC200 decrease over a larger area was found in the southwest
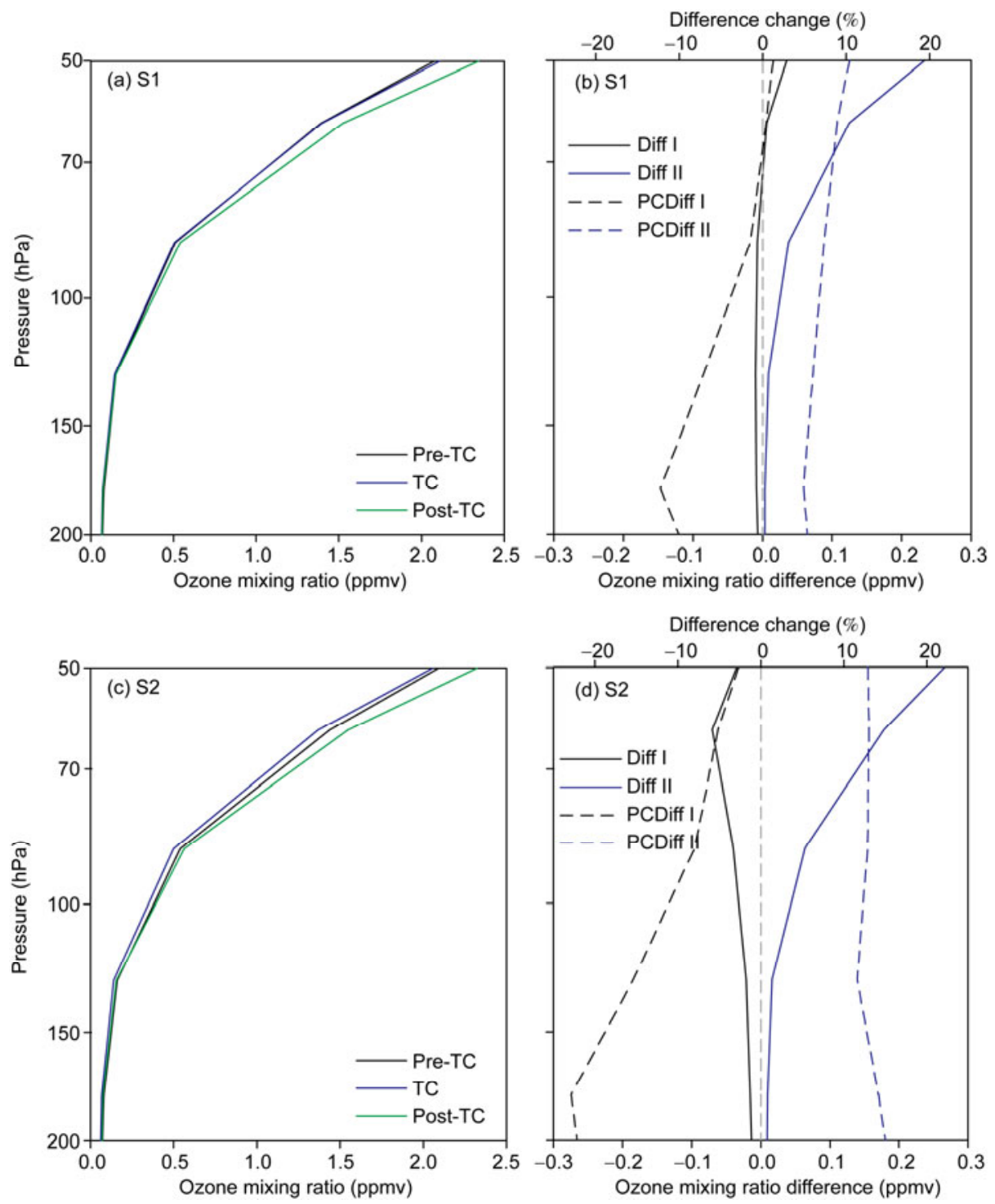

Figure 2 (a) and (c) Mean ozone profiles in S1 and S2 before (Pre-TC), during (TC) and after (Post-TC) Hai-Tang, respectively. (b) and (d) Differences (solid) and difference changes (dashed) of ozone profiles between typhoon and pre-typhoon (Diff I, PCDiff I) and between typhoon and post-typhoon (Diff II, PCDiff II) for S1 and S2, respectively. 
and southeast quadrants of Hai-Tang when the typhoon was stronger (Figure 1(d)). From the OC200 along line $A B$ (Figure 1(e)), it is seen that higher ozone of 256-265 DU occurred in pre-TC in contrast to lower ozone of 255-260 DU dominated the typhoon region $\left(20^{\circ}-22.7^{\circ} \mathrm{N}\right)$ in TC. The OC200 along line $A B$ were $267-275$ DU in post-TC. Along line CD (Figure 1(f)), OC200 prior to the arrival of typhoon was 256-261 DU. OC200 change attained to -5.5 DU. OC200 along line CD were $270-276$ DU in post-TC. OC200 changes in the cyclone activity region ( $-4.3 \mathrm{DU}$ on 13 July and -5.5 DU on 17 July) are larger than the OMI retrieval errors in stratospheric ozone columns down to $215 \mathrm{hPa}$ (1.6-4 DU) [18]. The magnitude and extent of the decrease in OC200 induced by the typhoon with higher intensity are larger than those by the weak typhoon.

To elucidate the variability of ozone profile induced by Hai-Tang, mean ozone profiles of regions S1 and S2 (Figure 1(c) and (d)) in three periods (pre-TC, TC and post-TC) are analyzed. As depicted in Figure 2(a) and (c), ozone decreased in TC in both $\mathrm{S} 1$ and S2. Furthermore, difference and difference change of ozone profiles between TC and pre-TC (TC minus pre-TC, Diff I) and that between TC and post-TC (post-TC minus TC, Diff II) are shown in Figure 2(b) and (d). Ozone decreased between 200 and $50 \mathrm{hPa}$ in Diff I in S1. The corresponding is about $-12 \%-2 \%$ change. During Diff II, ozone increase attained to $10 \%$ in the 50 $200 \mathrm{hPa}$. As for S2 in Figure 2(d), ozone decreased in the $50-200 \mathrm{hPa}$ during Diff I. The corresponding is about $-22 \%-$ $-3 \%$ change. During Diff II in S2, ozone increased between 50 and $200 \mathrm{hPa}$. The difference changes of ozone profiles in the cyclone activity region, $-12.2 \%$ at $175 \mathrm{hPa}$ on 13 July and $-22.9 \%--15.4 \%$ in $125-200 \mathrm{hPa}$ on $17 \mathrm{July}$, are evi- dent with the consideration of the uncertainties of $12 \%$ between $50-215 \mathrm{hPa}$ in OMI ozone profiles over the northern sub-tropics $\left(15^{\circ}-30^{\circ} \mathrm{N}\right)$ [17].

In order to depict the vertical structure of ozone in more detail, the anomalies in ozone mixing ratio between 50 and $200 \mathrm{hPa}$ along line $A B$ on 13 July and line $C D$ on 17 July are shown in Figure 3. The ozone anomalies are obtained from the mean ozone transection averaged from pre-TC to post-TC according to their own time series. Figure 3(a) illustrates that Hai-Tang caused a decrease in ozone mixing ratio from 200 to $50 \mathrm{hPa}$. In comparison with the category 1 typhoon on 13 July, the strong updraft $\left(\omega_{500}<-1 \mathrm{~Pa} \mathrm{~s}^{-1}\right)$ in the category 4 typhoon caused ozone being diluted from 200 to $50 \mathrm{hPa}$ with a larger magnitude on 17 July along CD. In addition, around the eyewall low PV values extend upward from the upper troposphere to the lower stratosphere on 17 July, suggesting the penetration of deep convection around the eyewall into the stratosphere.

In conclusion, based on the state-of-the-art OMI ozone profile, the impact of Typhoon Hai-Tang (2005) on stratospheric ozone was investigated in this study. The updraft extended vertically upward from upper troposphere indicates the presence of overshooting with ozone poor air that has penetrated into the stratosphere during the typhoon. A comparative analysis for different stages of Hai-Tang showed that the exchange process between troposphere and stratosphere is enhanced in the region where typhoon has a higher intensity. Further work based on higher resolution measurements and cloud-resolving model simulations are required to better understand the dynamical processes by which a typhoon contributes to the upper troposphere and lower stratosphere.
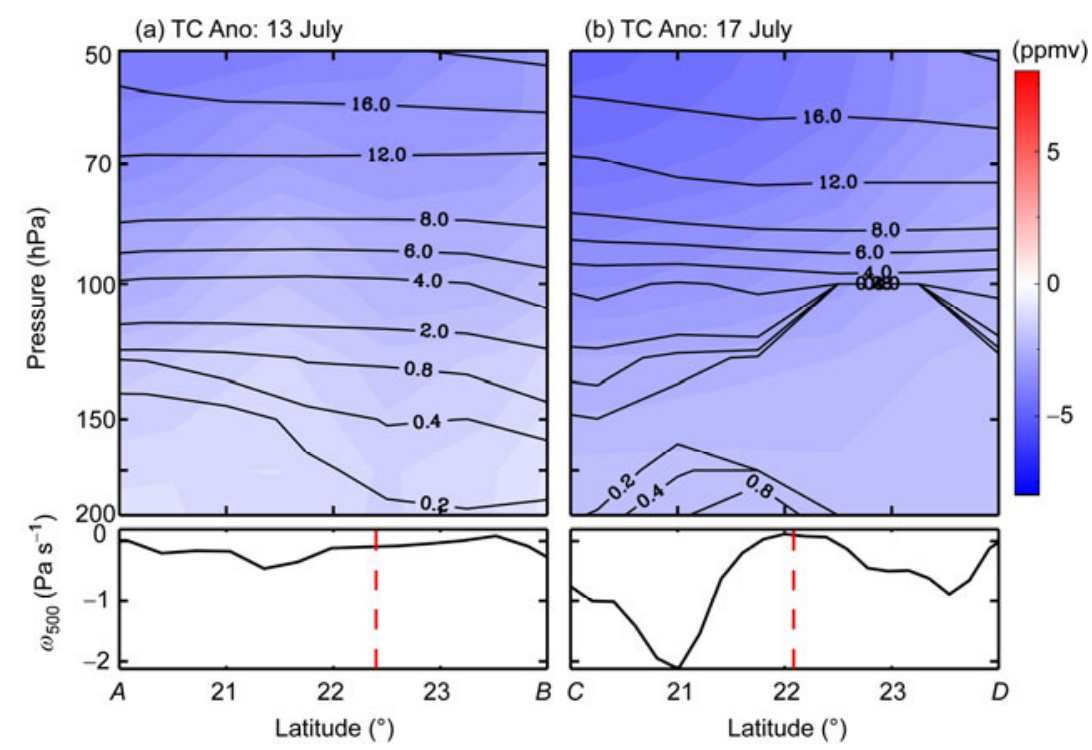

Figure 3 Ozone anomalies and potential vorticity (contours: $10^{6} \mathrm{~K} \mathrm{~m}^{2} \mathrm{~kg}^{-1} \mathrm{~s}^{-1}$ ) distribution between 200 and $50 \mathrm{hPa}$, and $\omega_{500}\left(\right.$ line plots: Pa s${ }^{-1}$ ) along lines (a) $A B$ and (b) $C D$ on 13 and 17 July, respectively. 
This work was supported by the National Basic Research Program of China (2010CB428601), the Knowledge Innovation Program of the Chinese Academy of Sciences (KZCX2-YW-Q11-04), and the National Natural Science Foundation of China (41230419 and 41075041). We thank NASA GES DISC for providing the ozone data, JAXA/EORC for the TRMM $2 A 25$ products, and NCEP and ECMWF for the meteorological reanalysis data. We also thank two anonymous reviewers for their constructive suggestions.

1 Rossow W B, Pearl C. Geophys Res Lett, 2007, 34, L04803

2 Romps D M, Kuang Z. Geophys Res Lett, 2009, 36: L09804

3 Penn S. J Appl Meteorol, 1965, 4: 212-216

4 Penn S. J Appl Meteorol, 1966, 5: 407-410

5 Baray J L, Ancellet G, Radriambelo T, et al. J Geophys Res, 1999, 104: 13953-13970

6 Carsey T P, Willoughby H E. Mon Weather Rev, 2005, 133: 166-174

7 Cairo F, Buontempo C, MacKenzie A R, et al. Atmos Chem Phys, 2008, 8: 3411-3426
8 Rodgers E B, Stout J, Steranka J, et al. J Appl Meteorol, 1990, 29 : 934-954

9 Stout J, Rodgers E B. J Appl Meteorol, 1992, 31: 758-783

10 Zou X, Wu Y. J Geophys Res, 2005, 110: D06109

11 Zhan R, Wang Y. J Geophys Res, 2012, 117: D12112

12 Joiner J, Vasilkov A, Yang K, et al. Geophys Res Lett, 2006, 33: L06807

13 Das S S. Geophys Res Lett, 2009, 36: L15821

14 Chan C Y, Li Y S, Tang J H, et al. Atmos Environ, 2007, 41: 3556-3564

15 Tsutsumi Y, Makino Y, Jensen J B. J Geophys Res, 2003, 108: 4251

16 Levelt P F, van den Oord G H J, Dobber M R, et al. IEEE Trans Geosci Remote Sensing, 2006, 44: 1093-1101

17 Kroon M, de Haan J F, Veefkind J P, et al. J Geophys Res, 2011, 116: D18305

18 Liu X, Bhartia P K, Chance K, et al. Atmos Chem Phys, 2010, 10 : 2539-2549

19 Vaughan G, Price J D. Q J R Meteorol Soc, 1991, 117: 1281-1298

Open Access This article is distributed under the terms of the Creative Commons Attribution License which permits any use, distribution, and reproduction in any medium, provided the original author(s) and source are credited. 